\title{
Correlation between the histopathological grade and size of breast cancer with axillary lymph node involvement
}

\author{
Tariq I. Al-Aubaidi* \\ Modaher Ahmed**
}

\author{
FIBMC, FACS \\ MBChB
}

\begin{abstract}
:
Background: Breast cancer account for $29 \%$ of all newly diagnosed cancer in female and is responsible for $14 \%$ of cancer related deaths in women. Breast cancer is basically detected either during a screening tests, before symptoms have appeared, or after a woman notices a mass. Overall risk doubles each decade until the menopause, when the increase slows down or remains stable.

JFac Med Baghdad 2017; Vol.59, No.4 Receive Nov. 2017 Accepted Feb.2018 lymph node.

Patients and methods: a continuous prospective study of 50 patients from 1st January 2016 to 1 st January 2017 in Baghdad teaching hospital at 1st surgical floor, where almost all patients with breast cancer operated on by modified radical mastectomy and axillary clearance included in the study.

Results: the commonest age group was 5 th decade with $32 \%$ of patients followed by 6 th decade with $28 \%$ of patients. The most common histological type was IDC with $78 \%$ and $22 \%$ of patients were ILC. The most common stage at presentation was stage II A with $32 \%$ of patients followed by stage III A with $28 \%$ of patients. Tumor size between $(2-5) \mathrm{cm}(\mathrm{T} 2)$ was the most common with $68 \%$ of patients. Grade II was the commonest histological grade in this study with $68 \%$ of patients. Axillary lymph nodes (ALN) involvement increase as tumor size increase, it was $50 \%$ in $\mathrm{T} 1,55.8 \%$ in $\mathrm{T} 2$, $88.8 \%$ in T3 and $100 \%$ in T4. Grade I associate with $25 \%+$ ve ALN, grade II $55.8 \%$ and $100 \%$ in grade III.

Conclusion: The majority of patients in this study were in fifth and sixth decades. There is delay in presentation of patients as evidenced by the most common tumor size being $\mathrm{T} 2$ and the most common stage being stage II A\& stage III A.IDC was the most common histological type. The most common grade was grade II. The larger the tumor the more incidence of ALN involvement, also the higher grade of the tumor associate with more ALN involvement.

Keywords: Breast cancer, staging, axillary lymph node, histopathological grade.
\end{abstract}

\begin{abstract}
Introduction
Breast cancer is the most common site-specific cancer in women and the leading cause of death from cancer for women aged 20 to 59 years. It account for $29 \%$ of all newly diagnosed cancer in female and is responsible for $14 \%$ of cancer related deaths in women (1). In 2010, approximately one \&three quarter million new cases were diagnosed worldwide. The incidence is expected to continue rising as population ages although more slowly than previously thought as the use of HRT had reduced in U.S.A \& U.K (2). Approximately $25 \%$ of new cancers are insitu.The rise in the detection of ductal carcinoma insitu is a result of the increased use of screening mammography, which detect breast cancers before they are palpable. The earliest sign of breast cancer is usually an abnormality on a mammogram. As breast cancer grow, they can produce a palpable mass that is often hard and irregular. Other signs may include thickening, swelling, skin irritation, or dimpling. Nipple changes due to breast cancer can include scaliness and dryness, ulceration, retraction, or discharge (3). Histologic types
\end{abstract}

Breast cancers are almost all carcinomas of the

*Dept. of Surgery College of medicine University of Baghdad, Email: tariqibrahimya@yahoo.com.

**Baghdad teaching hospital. breast that carry milk to the nipples) (4).

Noninvasive breast cancer: Noninvasive neoplasms of the breast are divided into two major types, LCIS and DCIS .LCIS is considered as a risk factor for development of breast cancer. One variant of LCIS, pleomorphic LCIS, has been recognized as a distinct and more aggressive subtype(5) .DCIS is more morphologically heterogeneous than LCIS , and pathologists recognize four types of DCIS; papillary ,cribriform, solid and comedo type. The four morphological types of DCIS are rarely seen as pure lesions; DCIS lesions are usually of mixed morphologic types (5)

Invasive breast cancer: Pathologists widely divide invasive breast cancer into ductal and lobular histologic types. Invasive ductal cancer tends to grow as a cohesive mass; it appears as a discrete shadow on a mammogram and is often palpable as a discrete lump in the breast smaller than lobular cancer. Invasive lobular cancer tends to permeate through the breast in a single - file nature; it remains occult \& failed to detect on mammography or clinical examination until the tumor is extensive. Invasive ductal carcinoma is the most common form of breast cancer, it accounts for $50 \%$ to $70 \%$ of invasive breast cancers. Invasive lobular carcinoma accounts for $10 \%$ of breast cancers. If the infiltrating cells, of invasive ductal carcinoma, form small 
glands lined by a single row of bland epithelium, they are called infiltrating tubular carcinoma. These lesions called mucinous or colloid tumors, each accounts for $2 \%$ to $3 \%$.Other types is medullary carcinoma which accounts for $5 \%$ of breast cancers (5) . Staging Five decades ago, Denoix et al. proposed classification system (tumor,node,metastasis TNM) based on the dissemination of cancer according to the features of the primary tumor(localization, size \&extension to the surrounding structures), regional lymph nodes, \& the presence of metastasis (6).

Pathologic staging: Pathologic staging includes all data used for clinical staging, surgical exploration and resection as well as pathologic examination of the primary carcinoma, regional lymph nodes, and metastatic sites (7)(8).

Primary tumor; Tumors should be measured to the nearest $0.1 \mathrm{~cm}$ increment.

-Tx Primary tumor cannot be assessed

-T0 No evidence of primary tumor

-Tis Carcinoma in situ

-T1 Tumor $2 \mathrm{~cm}$ or less in greatest dimension

-T2 Tumor greater than $2 \mathrm{~cm}$ but not more than $5 \mathrm{~cm}$ in greatest dimension

-T3 Tumor greater than $5 \mathrm{~cm}$ in greatest dimension

-T4 Tumor any size with direct extension to chest wall or skin Regional Lymph Nodes

-pNx Regional lymph nodes cannot be assessed

-pN0 No regional lymph node metastases histologically

-pN1 Micro metastases or metastases in 1-3 axillary lymph nodes

-pN2 Metastases in 4-9 axillary lymph nodes

-pN3 Metastases in 10 or more axillary lymph nodes Distant Metastasis (M)

-M0 No clinical or radiographic evidence of distant metastases

-M1 Distant detectable metastases as determined by classic clinical and radiographic means and/or histologically proved larger than $0.2 \mathrm{~mm}$.

\section{Table 1: Staging system}

\begin{tabular}{|c|c|c|c|}
\hline Stage 0 & Tis & No & M0 \\
\hline Stage I & $\mathrm{T} 1$ & NO & M0 \\
\hline \multirow[t]{3}{*}{ Stage II A } & T0 & N1 & M0 \\
\hline & $\mathrm{T} 1$ & N1 & M0 \\
\hline & $\mathrm{T} 2$ & No & M0 \\
\hline \multirow[t]{2}{*}{ Stage II B } & $\mathrm{T} 2$ & N1 & M0 \\
\hline & $\mathrm{T} 3$ & N0 & M0 \\
\hline \multirow[t]{5}{*}{ Stage III A } & T0 & $\mathrm{N} 2$ & M0 \\
\hline & $\mathrm{T} 1$ & $\mathrm{~N} 2$ & M0 \\
\hline & $\mathrm{T} 2$ & N2 & M0 \\
\hline & T3 & N1 & M0 \\
\hline & T3 & N2 & M0 \\
\hline \multirow[t]{3}{*}{ Stage III B } & $\mathrm{T} 4$ & No & M0 \\
\hline & $\mathrm{T} 4$ & N1 & M0 \\
\hline & $\mathrm{T} 4$ & N2 & M0 \\
\hline Stage III C & Any $T$ & N3 & M0 \\
\hline Stage IV & Any $T$ & Any N & M1 \\
\hline
\end{tabular}

Essentials of general surgery 2013 (3).
Grading of tumor: Histological tumor grade is a statistically significant prognostic factor for overall survival (9). Nottingham grading is done by assessing the nuclear grade, architectural grade and mitotic count (10). The histological grades of breast carcinoma are: Grade I: well differentiated carcinoma Grade II: moderately differentiated carcinoma Grade III: poorly differentiated carcinoma Grade is an estimate of the pace of growth. It is generally considered that the higher grade tumors have an increased frequency of lymphovascular invasion and lower survival rate. Tumors with a greater number of axillary lymph nodes positive for breast cancer metastasis are associated with poor prognosis (11).

\section{Patients and methods:}

This is a prospective study for 12 months duration from 1st January 2016 to 1st January 2017. The study was conducted in Baghdad teaching hospital at first surgical floor, where almost all patients with breast cancer operated on by modified radical mastectomy and axillary clearance were included in this study. Male patients with mastectomy for benign gynecomastia and mastectomy for carcinoma insitu were excluded. Detailed history, physical examination and investigations (included mammography \& ultrasound) done for patients. The sample of fifty modified radical mastectomy specimens undergoing histopathological evaluation of tumor type, size, grade and number of axillary lymph nodes involved by breast carcinoma, were enrolled in the study. Distribution of breast cancers by age, histological types tumor size, grade and stage were studied. Correlations between tumor size, histological types and grade with ALN were studied and $\mathrm{p}$ value of each was calculated. The Statistical Package for Social Sciences (SPSS program version 20) was used for data entry and analyses. Descriptive statistics were presented as numbers and percentages. Chi square test for independence was used to test the statistical significance of association between 2 categorical variables. P. value, of $\leq 0.05$, was considered as significant correlation.

\section{Results:}

A total of 50 patients of modified radical mastectomy with axillary clearance specimens were included in this study. Regarding age incidence, the commonest age group was the 5th decade $16(32 \%)$ of patients followed by the 6th decade with 14(28\%) of patients. 3 patients present in 3rd decade $(6 \%), 2$ patients in 8 th decade(4\%), 1 patient in 9 th decade and 7 patients present in 4 th $\& 7$ th decade $(14 \%)$ for each decade as shown in table2. The youngest age was 26 year while the oldest was 90 year. About the histological distribution, ductal carcinoma was the most common with 39 (78\%) of patients followed by lobular carcinoma with $11(22 \%)$ of patients. Among the patients of ductal carcinoma 33(85\%) were of NST subtype (no special type) followed by medullary 2 patients $(5 \%)$ and 1 patient of mucinous, comedo, papillary and solid with $2.5 \%$ 
for each one of these subtypes as shown in table2. Among the 50 patients, 32 (64\%) had +ve ALN and $18(36 \%)$ did not associate with ALN involvement. The relation between histological types and ALN ,shown in table 3, show ALN involvement in $66.6 \%$ in IDC \& $54.5 \%$ in ILC.P value was 0.02 which is statistically significant. Regarding distribution by stage at presentation, the most common stage was stage II A with $16(32 \%)$ of patients followed by stage III A with 14 (28\%) of the patients. Stage II B was present in $12(24 \%)$ patients, stage III B \&stage III $C$ present in $3(6 \%)$ patients for each stage, and the least stage present in the study was stage I A with $2(4 \%)$ of patients as shown in table2. About tumor size, the commonest was T2 with $34(68 \%)$ as shown in table $2 \&$ figure 2 ,of these 19 patients (55.8\%) associated with +ve ALN \& 15 (44.2\%) did not associate with ALN involvement.T1 cases were $4(8 \%)$ with $50 \%$ involvement of ALN. T3 patients were $9(18 \%)$ with $8(88.8 \%)$ associated with +ve LN \& $1(11.2 \%)$ had -ve axillary LN. T4 patients were 3 with $100 \%$ involvement of ALN as shown in table4. $\mathrm{P}$ value was 1.2 which is statistically significant Of the total number of patients, the commonest grade was grade II with 34 patients (68\%) as shown in table 2 \& figure 2 , of these $19(55.8 \%)$ associated with +ve ALN \& 15 (44.2\%) had -ve ALN. Grade I patients were $4(8 \%)$ with 1 patient associated with +ve ALN (25\%) \&3 patients did not associate with ALN involvement $(75 \%)$. Grade III in this study represent $24 \%$ (12) patients with $100 \%$ involvement of ALN as shown in table5. P value was 0.01 which is statistically significant.

Table 2: Patients distribution according to (age, histological type, stage, tumor size and grade).

\begin{tabular}{|c|c|}
\hline number & Percent \\
\hline \multicolumn{2}{|l|}{ Age } \\
\hline $20-30$ & $36 \%$ \\
\hline $31-40$ & $714 \%$ \\
\hline$\overline{41-50}$ & $1632 \%$ \\
\hline $51-60$ & $1428 \%$ \\
\hline $61-70$ & $714 \%$ \\
\hline $71-80$ & $24 \%$ \\
\hline $81-90$ & $12 \%$ \\
\hline \multicolumn{2}{|l|}{ Histological type } \\
\hline Ductal & $3978 \%$ \\
\hline -NST & $3385 \%$ \\
\hline -Medullary & $25 \%$ \\
\hline -Mucinous & $12.5 \%$ \\
\hline -Comedo & $12.5 \%$ \\
\hline -Papillary & $12.5 \%$ \\
\hline -Solid & $12.5 \%$ \\
\hline lobular & $1122 \%$ \\
\hline \multicolumn{2}{|l|}{ Stage } \\
\hline Stage I & $24 \%$ \\
\hline Stage IIA & $1632 \%$ \\
\hline Stage II B & $1224 \%$ \\
\hline Stage III A & $1428 \%$ \\
\hline
\end{tabular}

\begin{tabular}{lc}
\hline Stage III B & $36 \%$ \\
\hline Stage III C & $36 \%$ \\
\hline Tumor size & $48 \%$ \\
\hline T1 & $3468 \%$ \\
\hline T2 & $918 \%$ \\
\hline T4 & $36 \%$ \\
\hline Grade & $48 \%$ \\
\hline Grade I & $3468 \%$ \\
\hline Grade II & $1224 \%$ \\
\hline Grade III &
\end{tabular}

Table 3: Relation between histological types and axillary lymph involvement

\begin{tabular}{llllll}
\hline Type & ALN +ve & percent & ALN -ve & percent & P value \\
\hline Ductal & 26 & $66.6 \%$ & 13 & $33.4 \%$ & \\
\hline Lobular & 6 & $54.5 \%$ & 5 & $45.5 \%$ & 0.02 \\
\hline Total & 32 & $64 \%$ & 18 & $36 \%$ & \\
\hline
\end{tabular}

Table 4: Relation between tumor size and ALN involvement

\begin{tabular}{llllll}
\hline Tumor & ALN +ve & percent & ALN -ve & percent & P value \\
\hline T1 & 2 & $50 \%$ & 2 & $50 \%$ & \\
\hline T2 & 19 & $55.8 \%$ & 15 & $44.2 \%$ & 0.02 \\
\hline T3 & 8 & 88.8 & 1 & $11.2 \%$ & \\
\hline T4 & 3 & $100 \%$ & 0 & $0 \%$ & $36 \%$ \\
\hline Total & 32 & $64 \%$ & 18 & \\
\hline
\end{tabular}

Table 5: Relation of grade and ALN involvement

\begin{tabular}{llllll}
\hline grade & ALN +ve & percent & ALN -ve & percent & P value \\
\hline Grade I & 1 & $25 \%$ & 3 & $75 \%$ & \\
\hline Grade II & 19 & $55.8 \%$ & 15 & $44.2 \%$ & \\
\hline Grade III & 12 & $100 \%$ & 0 & $0 \%$ & 0.01 \\
\hline Total & 32 & $64 \%$ & 18 & $36 \%$ & \\
\hline
\end{tabular}

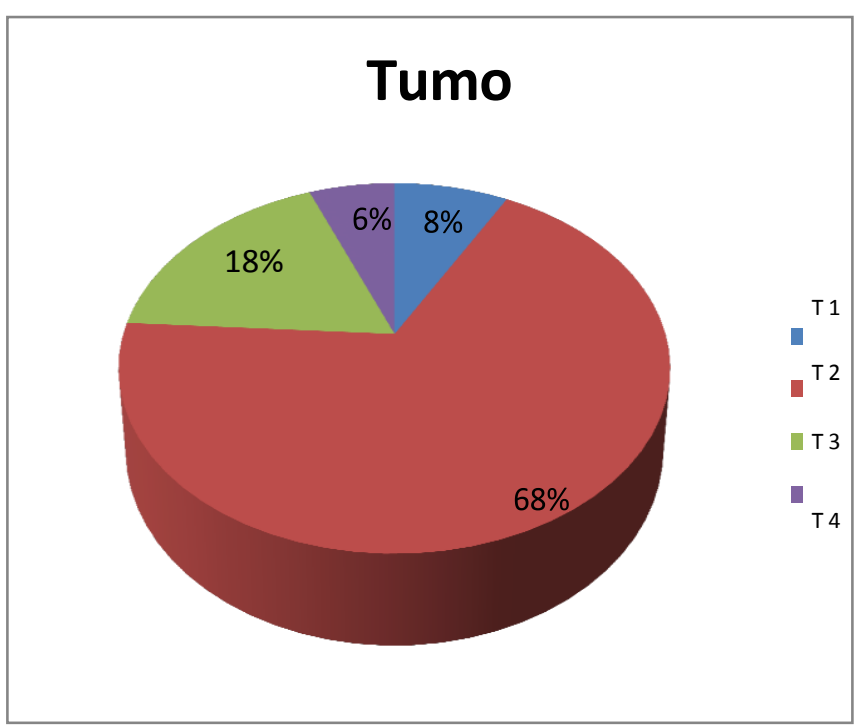

Figure 1: Tumor size 


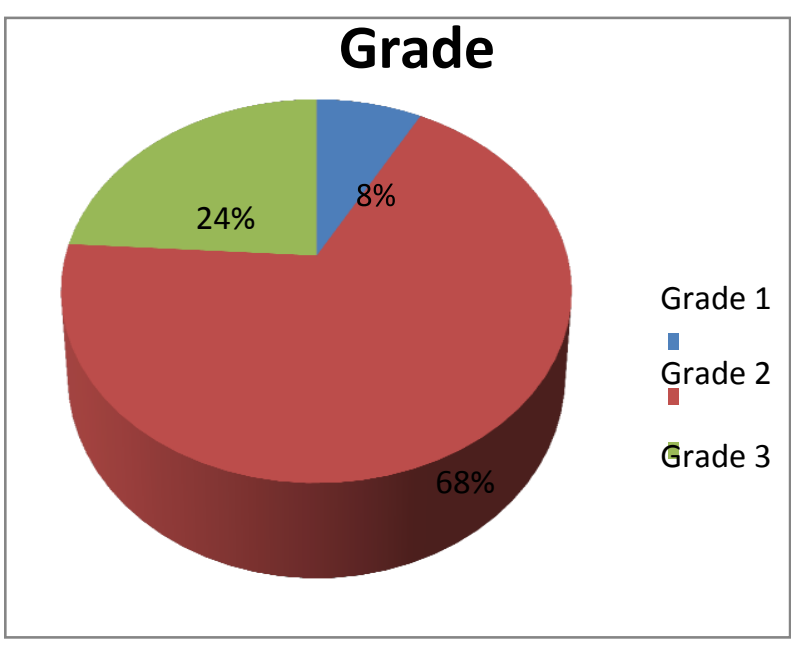

Figure 2: Grade of tumor

\section{Discussion}

In this study, the commonest age group was fifth decade which is comparable with Kerby I. bland (1) , Zhabg study (12) and result of Iraqi cancer registry (13) in which the 5th decade had the highest incidence, and incomparable with National cancer registry Ireland (2009)(14) which revealed that 6th decade was the most common age for breast cancer and this may show that environmental factors are important in the incidence of the disease. The second most common decade was 6th decade, which is comparable with international figures showed by Howlader $\mathrm{N}$ et al (15), and this reflect the effect of wide use of screening programs . Regarding the histological types of breast cancer, the most common type in this study was the invasive ductal carcinoma (IDC), with $78 \%$ of patients, followed by invasive lobular carcinoma (ILC), with $22 \%$ of patients, which is approximately resemble the international percentages, Kerby I.Bland(1) showing $80 \%$ for (IDC) \& $10 \%$ for (ILC) and in Nelson HD et al (16) which show $50-70 \%$ for (IDC) $\& 10 \%$ for (ILC). About the stage of tumor at presentation, the most common was stage II A with $16(32 \%)$ of patients which is comparable with the National Cancer Registry Ireland (2009) (14) and the second most common stage in this study was stage III A with $14(28 \%)$ of patients which is incomparable with National Cancer Registry Ireland (2009)(14) which show stage I the second most common stage and this indicate delay in presentation and lack of education about the disease in our society. Regarding the tumor size, the most common in this study was T2, with $34(68 \%)$ of patients followed by T3 with $9(18 \%)$ of patients and this is comparable with Egyptian study by Zaghloul AS et al(17)and differ from pakistanian study by Wahid Y et al(18) which show the T3 is the most common, also this study was incomparable with the study by Falkson G et al (19) , with T1 was the most common. This difference reflects the lack of awareness of early consultation for health problems in eastern countries. The correlation between tumor size and axillary lymph node(ALN) in this study showed that $50 \%$ of $\mathrm{T} 1$ had +ve ALN ,55.8\% for T2,88.8\% for T3 and
$100 \%$ for T4 which indicate that greater the size of tumor ,the more probability of +ve ALN as showed also by Nouh MA et al(20) which showed that 33.3 $\%$ of T2 had +ve ALN , $60.7 \%$ for T3 and $85 \%$ of T4. This study also is comparable with study by Riaz S. et al (21) which also showed $100 \%$ involvement of ALN in T4. Regarding the grade of breast cancer at presentation, the most common was grade II with $34(68 \%)$ of patients, which is comparable with Siddique MS et al (22) which also show the commonest grade was grade II with $56.6 \%$. About grade of tumor and its correlation with ALN,this study show that the higher the grade i.e. more malignant changes, the more +ve ALN , with $25 \%$ of grade I had +ve ALN, $55.8 \%$ of grade II and $100 \%$ of grade III had +ve ALN which is comparable to study by Mincey BA et al (23

\section{Conclusion}

There is delay in presentation of patients as evidenced by the most common tumor size being T2 and the most common stage being stage II A \&stage III A . IDC was the most common histological type. The most common grade was grade II. The larger the tumor the more incidence of ALN involvement, also the higher grade of the tumor associate with more ALN involvement.

\section{Authors' contributions:}

Prof. tariq al-aubaidi, data collection, main surgeon, patient follow up, manuscripts writing $\mathrm{dr}$ modaher ahmed, study design, literature review

\section{References}

1- Kirby I. Bland, M.D.Schwartzs .principles of surgery ed. 10. New York Mc Graw-Hill 2o15.chap.(17), the breast p. 517-543.

2- Sainsbury R. The breast: Williams N. Bulstrode C. O'Connell P. Bailey \& Love's . 26th edition . 2013 : chap (53) p.798-819.

3- Dunnington G. the breast : Lawrence P. Bell R. Dayton M. Essentials of general surgery . 2013 : chap (19) p.390-403

4- Fentiman Is ,fourquet $A$ and hortobagyi; Male breast cancer. Lancet Jun 2006: 367: 595 -604

5- Hunt K. Diseases of the Breast: Townsend C. Beauchamp R. SABISTON TEXTBOOK of SURGERY . 2017 : chap (33) p.820 -861.

6- Harris JR. Natural history and staging of breast cancer. In: Haris JR et al., editors. Breast diseases. Philadelphia: JB Lippincott Company; 1996.

7- Edge SB, Byrd DR, Compton CC, Fritz AG, Greene FL, Trotti A, editors. AJCC cancer staging manual. 7th ed. New York: Springer; 2009. p. 419 -60 .

8- Haffty BG, Buchholz TA, Perez CA. Early stage breast cancer. In: Halperin EC, Perez CA, Brady $L W$, editors. Principles and practice of radiation oncology. 5th ed. Philadelphia: Lippincott company; 2008. p. $1175-291$. 
9- Elston CW, Ellis IO, Pinder SE. Pathological prognostic factors in breast cancer. Cri Rev Oncol Haematol 1999; 31: 209-23.

10-Rampaul IS, Pinder SE, Elston CW, Ellis IO. Prognostic and predictive factors in primary breast cancer and their role in patient management. The Nottingham breast team. Eur J Surg Onc 2001; 27: $229-38$.

11-Elston, CW and Ellis IO. Assessment of histological grade. In Elston $\mathrm{CW}$ and Ellis IO. The breast. Churchill Livingstone: Edinburgh, 1998: 356 -84 .

12-Zhabg.C.Yu-X; Haung-S Study on Measures to increase Diagnosis accuracy os FANC of breast masses. Chung-Hua. Ping-Li-I Isuch-Tsa-Chih, 1997; 26 (6): P.334 -6.

13-Result of Iraqi Cancer Registry 1994. 1995. 1997.2004

14-Breast cancer incidence, mortality, treatment and survival in Ireland: 1994 -2009. National Cancer Registry, Cork, Ireland (2012)

15-Howlader N. Noone AM, et al. eds SEER Cancer Statistics Review, 1975 -2010. Bethesda, MD: National Cancer Institute; 2003.

16-Nelson HD, Tyne K, Naik A, et al: Screening for breastcancer: An update for the U.S. Preventive Services Task Force.Ann Intern Med 151:727 737, W737-742,

2009.

17-Zaghloul AS, Ghoneim WA, Moneim TA, Kaddah NT, Bolkainy N, Khafagy MM. Patterns of Axillary Lymp $h$ node metastasis from breast cancer in Egyptian patients. $J$ Egyptian Nat Cancer Inst 2001; 13: 1 -8.

18-Wahid Y, Mushtaq S, Khan AH, Malik IA, Mamoon N. A morphological study of prognostic features in carcinoma breast. Pak J Pathol 1998; 9: $9-13$.

19-Falkson G, Gelman RS,Leon L, Falkson $\mathrm{Cl}$. Survival of Premenopausal women with breast cancer. Cancer1990;66:1621-29.

20-Nouh MA, Ismail H, Ali el-din NH, Bolkainy MN. Lymph node metastasis in Breast Carcinoma: Clinicopathologic correlation in 3747 Patients. J Egypt Nat Can Inst 2004; 16: 50-6.

21-Riaz S. Waris E. Correlation of Tumor Size and Grade With Axillary Lymph Node Status in Carcinoma Breast .Proceeding S.Z.P.G.M.I 2009. 23(1):29 -34.

22-M.Shahid Siddiqui et al; Faculty of Health Sciences Breast Carcinoma in Pakistan Female Morphological Study of 272 cases. Journal of Medical Association 2001;286: (11) P. 30 -2.

23-Mincey BA, Bammer T, Atkinson EJ, Perez EA. Role of Axillary Node Dissection in patients with T1a and T1b Breast Cancer. Arch Surg 2001; 136: $779-82$. 